- about OSH among stakeholders and stakeholder networks/ linkages

- Inadequate OSH infrastructure and OSH professional capacities to manage emerging health risks

- Addressing the NCD burden through Workplace Wellness Movement

Opportunities are:

- Utilisation of primary health care ecosystem for delivery of BOHS for informal sector

- Accreditation Mechanism under Ministry of Labour

- Regulatory framework under Factories' Act and governance apparatus under National Skills' Mission to develop requisite OSH human resources

- Corporate Social Responsibility initiatives to set up Risk Observatory Mechanisms with multisectoral linkages

\section{7e HOW WE PROMOTE PARTICIPATORY MULTIFACETED WORKPLACE IMPROVEMENTS FOR AVOIDING OVERSTRAINED WORK KNOWN AS 'KAROSHI'}

\footnotetext{
${ }^{1}$ Toru Yoshikawa, ${ }^{2}$ Kazutaka Kogi. ' National Institute of Occupational Safety and Health, Kawasaki, Japan; ${ }^{2}$ The Ohara Memorial Institute for Science of Labour, Tokyo
}

10.1136/oemed-2018-ICOHabstracts.864

Overwork-related disorders, such as cerebrovascular/cardiovascular diseases (CCVD) and mental disorders due to overwork known as 'Karoshi', are a major occupational and public health issue in East Asian countries. The Japanese Government passed the 'Act on Promotion of Preventive Measures against Karoshi and Other Overwork-Related Health Disorders' in June 2014 to develop a national initiative towards the prevention of overwork-related disorders. A part of the frame of the Law, National Institute of Occupational Safety and Health, Japan (JNIOSH) has been started researches for compensation claims related to overwork-related disorders. A picture of victims of Karoshi revealed the need for workstyle reform and promoting comprehensive occupational health services in Japan.

Participatory workplace improvement programs spreading to various sectors should be a key solution against overworkrelated disorders. A recent trend is to apply participatory programs for preventing work stress. Emphasis is usually placed on conducting multifaceted workplace improvements that have real impact on avoiding overstrained work. The reviewed programs for healthcare workers, local government employees and small and medium sized enterprises followed the guidelines for stress prevention programs concerning learning local good practices, addressing multifaceted stress-related risks and taking workplace-level group-work steps. A clear focus of these programs is placed on low-cost actions for improving internal communication, working schedules and teamwork methods. Improvement in these aspects accounted for the majority of improvements. Participatory steps focusing on feasible actions reflecting local good practices are effective for achieving these multifaceted improvements.

For preventing work stress by avoiding overstrained work, it is suggested to organise participatory group-work steps in each workplace by using locally adapted action checklists reflecting these multifaceted actions. Collecting good examples in comprehensive occupational health programs focusing on overwork-related disorders and exchanging these experiences contribute to workers' safety and health in Asia.

\section{$1667 f$ THE STRENGTHENING OF OSH REGULATION IN INDONESIA TO IMPROVE THE OCCUPATIONAL DISEASES MANAGEMENT}

Muchtaruddin Mansyur. University of Indonesia, Jakarta, Indonesia

\subsection{6/oemed-2018-ICOHabstracts.865}

Introduction Currently, Indonesia have been facing the triple burden of diseases including Communicable Diseases, Non Communicable Diseases, and Environmental/Occupational Accidents/Diseases. However, Occupational Diseases are still under reporting. This presentation is aimed to show the importance of the strengthening the regulation aspect toward a better Occupational Diseases Management.

Method Article review of the practice of Occupational Diseases management, and the policy and regulation in relation with the Occupational Health and Safety in Indonesia were used to explore the implementation and its challenges.

Result The National Workers Social Security Agency in 2015 compensated Occupational Accidents of 110.285 cases with spent the cost of IDR 661 Billion. However due to under diagnosed only less than 10 cases per year as the compensated cases of occupational diseases for 5 consecutive years, one of the weaknesses is the lack of regulation and guideline of Occupational Diseases Management. In 2014, Indonesian Government implemented the National Social Security included National Health Insurance and National Workers Social Security. 2016, the Ministry of Health of the republic Indonesia launched the Ministry Decree concerning Occupational Diseases management, and Threshold Limit Value of physicals and chemical exposures at the workplace.

Discussion The regulation of Occupational Diseases management, and Threshold Limit Value of physicals and chemical exposures at the workplace as further guidance for the OHS professionals in practicing the improvement of the management and control of Occupational Diseases in the context of National Social Security and Universal Health Coverage in Indonesia.

\section{OCCUPATIONAL SAFETY AND HEALTH IN LATIN AMERICA: STATE OF THE ART AND FUTURE CHALLENGES}

Elia L Enriquez*. National Institute of Occupational and Environmental Health Mexico, Mexico City

\subsection{6/oemed-2018-ICOHabstracts. 866}

Aim of special session To review the challenges, progress and priorities in Occupational Safety and Health in some countries in Latin America

Jorge A. Morales-Camino MD, MS, PhD, FACOEM ${ }^{1}$, Juárez-García, Arturo. $\mathrm{PhD}^{2}$, Claudia M. de Hoyos ${ }^{3}$

${ }^{1}$ Medical Director of Procter and Gamble Latin America, Mexico City, Mexico

${ }^{2}$ Centro de Investigación Transdisciplinar en Psicología, Universidad Autónoma del Estado de Morelos, México

${ }^{3}$ SMTBA, Mas Vida Salud. Buenos Aires Argentina 